may seem strange to the layman that experts should disagree on whether the Universe will perpetually continue to cool down, to attain inexorably the ultimate energy crisis, or whether it is destined to overheat and implode into a brilliant fireball, hotter and more intense than anything imaginable by human beings. The uncertainty arises because the currently available indicators are often contradictory; the cosmologist has considerable scope for rejecting evidence that may not fit his model, especially if the evidence is incomplete and tentative. A choice still remains between the "Heat Death" of the Universe and the "Big Squeeze".

Yet our knowledge of the Universe is increasing at an unprecedented rate. The availability of observatories in space has enabled astronomers to study the Universe over much of the electromagnetic spectrum that is inaccessible from ground level, from gamma-rays to infrared radiation. And modern technology has revolutionized ground-based observing. The caricature of the earnest astronomer peering through a telescope in a cold, dark observatory dome is a myth that has long been displaced.

The modern astronomer punches in coordinates on a computer console and views the stars on a video display in a brightly lit room crammed with sophisticated electronic instrumentation. The aim is to probe ever deeper into the mysteries of the Universe, by furthering our understanding of the structures within it, from stars to galaxies, alone and in their great clusters.

Astronomers are now able - albeit barely so - to trace images of ordinary galaxies so distant that their light was emitted before the Earth was formed. In principle, with sufficient information about such systems, one could directly infer their distances and decide whether the rate of expansion of the Universe has changed significantly over this time-scale. The future of the Universe could then be predicted unambiguously. It seems likely that within the next one or two decades, provided that governments continue to make the necessary commitment to science, advances in technology, both ground-based and in space, will enable detailed studies to be made of remote galaxies at the observable edge of the Universe.

The State of the Universe, based on the Wolfson College Lectures given at Oxford in the Spring of 1979 , provides a fascinating and highly readable account of several of the major developments that have taken place in astronomy and cosmology over the past decade. Eight leading scientists who have played key roles in many of the discoveries cover a diverse array of topics, ranging from G.E. Hunt on the exploration of the planets to D.W. Sciama on the origin of the Universe. Especially memorable is the contribution by $\mathrm{R}$. Penrose on black holes, for its lucid account of space-time singularities. M.J.
Rees writes on galaxies, their nuclei and their origin, and R.J. Tayler describes current views on the origin of the chemical elements. Hunt's beautifully illustrated chapter is one of the highlights of the book, providing a full and timely account of the newly acquired knowledge of the planets from Mercury to Jupiter. Remaining chapters include D.E. Blackwell on the stars as suns, K.A. Pounds on the X-ray Universe and F.G. Smith on new ways of seeing the Universe. Geoffrey Bath is to be commended on having co-ordinated an extraordinary lucid array of timely contributions from a group of the most eminent, and certainly among the busiest, of British astrophysicists.

On reading The State of the Universe one cannot fail to be impressed by the immense vistas that the explosive progress in astronomy has revealed. Much is poorly understood: indeed, a radically new approach to physics may be required if we are to discover the origin of the Universe, for example. But enough has fallen into place for us to be confident that our theories enable us to understand how much of the Universe entered into its present state. Prediction of its future evolution now becomes feasible. We can already do this for stars: it may not be long before enough data is at hand to determine definitively the future of the Universe, no less.

Joseph Silk is Professor of Astronomy at the University of California, Berkeley, and author of The Big Bang, published earlier this year by W.H. Freeman.

\title{
Tuning in to astronomy
}

\section{David W. Hughes}

Starseekers. By Colin Wilson. Pp.271. (Hodder and Stoughton/Doubleday: 1980.) £10.95, $\$ 15.95$.

Colin Wilson, the Colin Wilson who wrote The Outsider, Introduction to the New Existentialism, Strange Powers and a host of other titles, has now turned his attention to astronomy. He has written a fascinating account of how he thinks astronomers tick today, did tick in the past and should tick in the future, if, that is, they ever wish to solve the "fundamental question". What is the question? Bertrand Russell once said that the aim of philosophy is to understand the Universe. Wilson urges us to go a step further. The question is not just "what is the Universe?". It is "what is the purpose of the Universe?'. Purpose, a word that makes all good scientists shudder. How should we - dry, dusty, intellectual astronomers, tied to our telescopes, computers and respectable thought processes - delve into the understanding of the purpose of things? Wilson reveals his answer by frequent use of such phrases as "flashes of second sight", "supra-logical processes", "paranormal" and "intuitive insight". We are not told to abandon our scientific principles, we are simply encouraged to recognize that they are incomplete. There is always more than meets the eye.

The book divides into three sections. The first is a review of ancient cosmologies. Why should our ancestors build Stonehenge, what was the real purpose of the pyramids, did the ancient Egyptians know about the precession of the equinoxes? Wilson refers often to bicameralism and has obviously been much affected by Julian Jaynes's book The Origin of Consciousness in the Breakdown of the

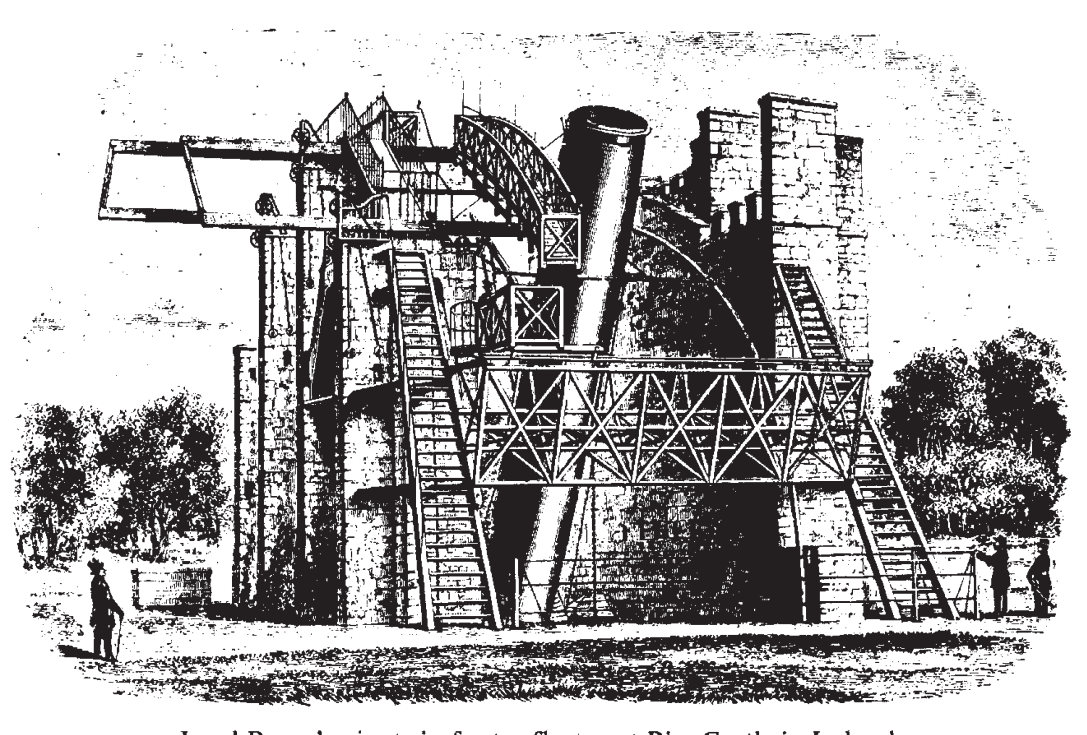

Lord Rosse's giant six-foot reflector at Birr Castle in Ireland 
Bicameral Mind. The brain is apparently split into a left half which is the home of rationalist, logical and scientific thought and a right half which houses artistic feelings and intuitive insights. Human development has led to a changeover in the dominant section. Civilization has suppressed the messages from the right brain and allowed the left brain to take over.

The second section of the book deals with the life histories and scientific achievement of some of the great renaissance scientists, Copernicus, Brahe, Kepler, Galileo, Newton and Hershel. The ghosts of Koestler's The Sleepwalkers and Dreyer's A History of Astronomy from Thales to Kepler haunt these pages.

The third section brings us firmly to the present day and traces the acceleration of astronomical discovery that has occurred since Einstein's gravitational theory and the advent of quantum mechanics. Planetary exploration, radio astronomy, big bang cosmology, black holes, the origin of life - all are touched upon. Throughout the text echoes the Wilson message that there is more to our astronomical Universe than science can understand. The investigators must try and tune into this ethereal suprahuman influence on our destiny in a manner similar to that used by our ancient ancestors.

I enjoyed reading this book. It was fun. The style is excellent, the production standard and the illustrations are superb. But I continually had an uneasy feeling. It is an axiom that you should not believe all that you read; the reader of this book should not, and Colin Wilson should not either. $\mathrm{He}$ has a regrettable tendency to regard the printed word in the same light as the tablets of Moses. Many eminent authors are quoted - Hoyle, Koestler, Motz, Taylor. When discussing Hoyle's Lifecloud and Ten Faces of the Universe, Wilson states that "No-one is going to quarrel with what they say". What? Scientists always question what other people say. The scientists such as Galileo, Kepler and Newton who are discussed in Wilson's book thrived on it. So should the readers of Starseekers.

But still, I congratulate Colin Wilson. Once you pick the book up it is hard to put it down. Interesting thoughts and problems sparkle from every other page.

David W. Hughes is a Lecturer in Astronomy and Physics at the University of Sheffield.

\section{James Six and his thermometer}

\section{W. D. Hackmann}

The Construction and Use of a Thermometer. By James Six. Introduction by Jill Austin and Anita McConnell. Pp.123. (Nimbus: London, 1980.) £15.

THIS small book reproduces the papers of an almost totally forgotten eighteenth century man of science, James Six (1731 1793), the descendant of a refugee Walloon family of silk weavers who settled in Canterbury during the reign of Elizabeth I. He was one of a score of amateur scientists who, through their individual small contributions, made scientific progress possible during the eighteenth century.

His tastes were typical of the contemporary intelligensia; painting, astronomy, electrical experiments with the new-fangled frictional electric machines, and meteorological observations. $\mathrm{He}$ invented a maximum and minimum selfregistering thermometer in 1780; a worthwhile contribution for which he was awarded a Royal Society Fellowship in 1792. His thermometer, in which the extremes of temperature were recorded by sliding indexes, has survived as a popular domestic instrument. With it he observed the night-time inversion of temperature, a phenomenon not explained by meteorologists until the following century.

The largest portion of the book is taken up with a reproduction of Six's Construction and Use of a Thermometer, published in 1794 , and essentially a summary of his three papers on thermometry published in the Philosophical Transactions with the addition of a chapter on the deep-sea use of his instrument. Eight pages are devoted to his other scientific communications. The bulk of these are his seven letters to the Gentleman's Magazine, a popular organ for the amateur scientist. In 1770 he described a comet later known as Lexell's Comet. Its orbit was calculated by the American astronomer David Rittenhouse and Six's observations largely agreed with this. In 1771 and 1781 he recorded the appearance of two other comets. Other topics dealt with were the 1784 heat wave, William Herschel's recently discovered "Georgian Star"' (Uranus) and a severe frosty spell in 1789. Also reproduced is a letter from the archives of the Cambridge University Library, written in 1785 by Six to a student friend of his son on the use of his thermometer. This series is terminated by a charming obituary of Six, also from the Gentleman's Magazine.

The only Six-type thermometer known before the researches of Austin and McConnell was the one in the Museum of the History of Science at Oxford. However, it is not contemporary, having probably been made in the 1820 s for Charles Daubeny whose chemistry laboratory was housed in the present basement of this Museum. The authors have identified 26 thermometers made by Six and now part of the King George III Collection at the Science Museum in London, and another specimen of obscure origin at the Copernicus Museum in Rome. These are described in some detail and the subsequent development of the instrument is also given.

All in all, this small, attractively-bound volume not only adds a little to the history of thermometry, it also gives us another glimpse into the world of eighteenthcentury men of science.

W. D. Hackmann is Assistant Curator of the Museum of the History of Science, University of Oxford. 